\title{
The prevalence of diabetes-related complications and multimorbidity in the population with type 2 diabetes mellitus in the Basque Country
}

\author{
Edurne Alonso-Morán ${ }^{1 *}$, Juan F Orueta ${ }^{2}$, Jose Ignacio Fraile Estebann ${ }^{3}$, José M Arteagoitia Axpe ${ }^{4}$, \\ M Luz Marqués González ${ }^{5}$, Nuria Toro Polanco ${ }^{1}$, Patxi Ezkurra Loiola ${ }^{6}$, Sonia Gaztambide ${ }^{7,8,9}$ \\ and Roberto Nuño-Solinis ${ }^{1}$
}

\begin{abstract}
Background: Type 2 diabetes mellitus is associated with a diverse range of pathologies. The aim of the study was to determine the incidence of diabetes-related complications, the prevalence of coexistent chronic conditions and to report multimorbidity in people with type 2 diabetes living in the Basque Country.

Methods: Administrative databases, in four cross sections (annually from 2007 to 2011) were consulted to analyse 149,015 individual records from patients aged $\geq 35$ years with type 2 diabetes mellitus. The data observed were: age, sex, diabetes-related complications (annual rates of acute myocardial infarction, major amputations and avoidable hospitalisations), diabetes-related pathologies (prevalence of ischaemic heart disease, renal failure, stroke, heart failure, peripheral neuropathy, foot ulcers and diabetic retinopathy) and other unrelated pathologies (44 diseases).

Results: The annual incidence for each condition progressively decreased during the four-year period: acute myocardial infarction ( 0.47 to $0.40 \%)$, major amputations ( 0.10 to $0.08 \%)$, and avoidable hospitalisations (5.85 to $5.5 \%)$. The prevalence for diabetes-related chronic pathologies was: ischaemic heart disease (11.5\%), renal failure (8.4\%), stroke (7.0\%), heart failure (4.3\%), peripheral neuropathy (1.3\%), foot ulcers (2.0\%) and diabetic retinopathy (7.2\%). The prevalence of multimorbidity was $90.4 \%$. The highest prevalence for other chronic conditions was $73.7 \%$ for hypertension, $13.8 \%$ for dyspepsia and $12.7 \%$ for anxiety.
\end{abstract}

Conclusions: In the type 2 diabetes mellitus population living in the Basque Country, incidence rates of diabetes complications are not as high as in other places. However, they present a high prevalence of diabetes related and unrelated diseases. Multimorbidity is very common in this group, and is a factor to be taken into account to ensure correct clinical management.

Keywords: Diabetes-related complications, Diabetes-unrelated pathologies, Multimorbidity, Type 2 diabetes

\section{Background}

The prevalence of type 2 diabetes is increasing worldwide [1], probably due to a longer life expectancy of the general population, a sedentary lifestyle and, above all, to increasing obesity. Prevalence in Spain has been estimated at 13.8\% (43\% unknown diabetes) [2].

Diabetes is a chronic disease that leads to high morbidity and mortality resulting from the complications that

\footnotetext{
* Correspondence: edurne.almo@gmail.com

'O + berri, Basque Institute for Healthcare Innovation, Torre del BEC (Bilbao Exhibition (entre), Ronda de Azkue 1, 48902 Barakaldo, Spain

Full list of author information is available at the end of the article
}

develop during its clinical course. Patients with diabetes are twice as likely to develop cardiovascular disease compared to the general population of the same age and sex, and this risk remains the same after adjustments for other traditional cardiovascular risk factors (CVRFs) [3]. Moreover, it is the leading cause of death in $80 \%$ of patients with diabetes in comparison to $30 \%$ in the general population [4]. This excess mortality is higher in women than in men $[3,5,6]$, and life expectancy is shortened by 7-10 years [7].

Incidences of chronic diabetes-related complications have been related to poor metabolic control, disease 
duration and the presence of associated CVRFs [8-10], although these factors account for only a part of this increased cardiovascular risk [6]. Early and aggressive management of the disease is required to reduce cardiovascular events and improve prognosis [11] which, in the Spanish context, is supported by means of the strategic plan developed by the Spanish National Health System (SNS) [12].

An association has been found between the increase in comorbidities and a greater use of health services [13-15]. Many patients with type 2 diabetes also have other chronic diseases interfering in the management of the disease, patient education and affecting health outcomes. Previous studies have examined coexisting chronic pathologies in patients with type 2 diabetes mellitus [16,17].

Therefore, this study aims to determine the prevalence and incidence of diabetes-related complications, as well as to provide a description of the multimorbidity of this group in the Basque Country.

\section{Methods}

The study protocol was approved by the Clinical Research Ethics Committee of Euskadi (PI2014074), Spain. Informed consent was not obtained because patient health records were made anonymous and deidentified prior to analysis.

A descriptive study was performed which included all patients with type 2 diabetes mellitus treated at Osakidetza - the Basque Health Service. The Basque Autonomous Community (BAC) has a public and universal health system, where the Department of Primary Care acts as a gatekeeper to access to other departmental services.

For this study, the demographic and clinical variables information was obtained from the PREST database. In such database, diagnoses are coded according to the International Classification of Diseases (ICD-9-CM) [18], and the coding system used for drugs is the Anatomical, Therapeutic, Chemical (ATC) classification system [19]. PREST is the database of the Stratification Programme which commenced in 2010 with the aim of classifying all Basque citizens using the Johns Hopkins Adjusted Clinical Groups (ACGs) case-mix system. This case mix enables health problems to be identified from diagnoses and prescriptions and patients to be categorised according to their healthcare needs. PREST therefore combines information from different sources (primary, specialty, emergency and inpatient care) to obtain clinical variables, prescriptions and procedures. A more detailed description is found in previous publications [20].

The identification of all patients with type 2 diabetes mellitus was based on selecting everybody who, according to the PREST database, had been diagnosed with type
2 diabetes mellitus or unspecified diabetes mellitus (including its complications) at any point in their lives, or who had been prescribed antidiabetic medication, regardless of whether or not they had visited healthcare services during the observation period (September 2007 August 2011). Excluded from this group were patients who had been diagnosed with type 1 diabetes mellitus during any contact with the services, or those whose diagnosis always corresponded to unspecified diabetes mellitus, but the only medication received was insulin. Although type 2 diabetes can occur at any age [21], it is more common after age 40; patients aged under 35 were excluded.

Successive 12-month time periods were established (year 1: from 01-09-2007 to 31-08-2008; year 2: from 01-09-2008 to 31-08-2009; year 3: from 01-09-2009 to 31-08-2010; year 4: from 01-09-2010 to 31-08-2011). During each time period, a patient was considered as presenting type 2 diabetes mellitus if the illness onset date was prior to the established cut-off point (i.e. prior to 01-09-2007, or prior to 01-09-2008 and so on), and in addition, the patient had to have public insurance at the start of the year (although not necessarily for the whole year). Thus, the number of patients considered as having type 2 diabetes mellitus was 116,295 in year $1 ; 123,991$ in year 2; 130,554 in year 3 and 134,421 in year 4 . The total study population (people with type 2 diabetes mellitus in any of these years) was 149,015.

\section{Variables and analysis}

The study variables were age, sex and existence of complications and comorbidities (whether or not related to type 2 diabetes mellitus). Hospital discharge records were used to study the incidence of complications (Minimum Basic Data Set [MBDS]) [22]. Hospital admission because of acute myocardial infarction, major amputation or avoidable hospitalisations (Ambulatory Care Sensitive Conditions [ACSC]) [23] was determined separately for each observation period.

To study the chronic diseases, a list of 52 health problems was developed and specific criteria were defined to consider that particular disease as active during the period from $01 / 09 / 2010$ to $31 / 08 / 2011$ by adapting a methodology previously reported by other authors [24]. In most cases, criteria were based on considering that a person has a chronic disease because they have been assigned the corresponding diagnosis (for example, hypertension); for some illnesses other criteria were applied: diagnosis or prescription of specific medications (e.g., for hypothyroidism and Parkinson's); repeated diagnosis over several years (low back pain); any history of the diagnosis together with prescription of specific drugs in the previous year (asthma and epilepsy); diagnosis 
Table 1 Incidence of complications of type 2 diabetes over the study period

\begin{tabular}{llllll}
\hline & \multicolumn{3}{c}{ Incidence (\%) } \\
\cline { 2 - 6 } Type 2 diabetes complications & Year 1 & Year 2 & Year 3 & Year 4 & Percentage increase from year 1 to 4 \\
\hline Myocardial infarction & 0.47 & 0.43 & 0.43 & 0.40 & -13.64 \\
Major amputations & 0.10 & 0.10 & 0.09 & 0.08 & -23.75 \\
Avoidable hospitalisations (all causes) & 5.85 & 5.66 & 5.41 & 5.50 & -5.99 \\
Avoidable hospitalisations because of DM & 0.62 & 0.60 & 0.54 & 0.51 & -18.14 \\
\hline
\end{tabular}

the previous year or repeated prescriptions over several months (depression and anxiety); or repeated prescriptions to treat the given health problem (treated dyspepsia). Further information of this methodology can be found in previous publications [25]. From such 52 health problems list, diabetes mellitus was excluded, and such group was split in two parts: 1) Related chronic comorbidities, that , according to the bibliography [8], included 7 pathologies: ischaemic heart disease, renal failure, stroke, heart failure, peripheral neuropathy, foot ulcers and diabetic retinopathy; and 2) unrelated chronic diseases, that corresponds to the remaining 44 health problems of the list.

The link to this database was feasible for $93 \%$ of patients with type 2 diabetes mellitus in year 4 ; therefore, the number of people in which these pathologies was established was limited to 126,894 .

To analyse the data, the incidence or prevalence of the aforementioned pathologies were estimated in the different population strata according to age and sex. Logistic regression determined the effect of the independent variables (sex and age groups) on the coexistence of such pathologies. To see whether there are differences between sexes in the distribution of diseases, the Pearson $X^{2}$ test was performed. Reported $P$ values under 0.05 were considered statistically significant.

Statistical calculations were performed using Stata Data Analysis and Statistical Software, Release 12 (StataCorp, LP, College Station, TX, USA).

\section{Results}

Evolution of the incidence of diabetes-related complications

It was observed that the incidence of diabetes-related complications has declined over the past four years. The number of major amputations performed (-23.8\%) and the number of acute myocardial infarctions $(-13.6 \%)$ have decreased, among others. All this information is contained in Table 1.

\section{Diabetes-related chronic pathologies}

For year 4 of the study, the chronic complications of patients with type 2 diabetes are shown in Table 2. It was observed that the prevalence of renal failure, heart failure, peripheral neuropathy, and foot ulcers was higher in

Table 2 Prevalence and incidence of diabetes-related complications in year 4 (September 2010- August 2011)

\begin{tabular}{|c|c|c|c|}
\hline \multirow[b]{2}{*}{ Type 2 diabetes complications } & \multicolumn{3}{|c|}{ Prevalence (\%) } \\
\hline & Total $(\mathrm{N}=134,421)$ & Males $(\mathrm{N}=72,539)$ & Females $(N=61,882)$ \\
\hline Ischaemic Heart Disease & 11.45 & 14.54 & 7.83 \\
\hline Renal failure & 8.37 & 8.35 & 8.40 \\
\hline Stroke & 6.96 & 7.42 & 6.42 \\
\hline Heart Failure & 4.32 & 3.93 & 4.79 \\
\hline Peripheral neuropathy & 1.33 & 1.24 & 1.44 \\
\hline Foot Ulcers & 1.93 & 1.76 & 2.13 \\
\hline \multirow[t]{2}{*}{ Retinopathy } & 7.18 & 7.18 & 7.18 \\
\hline & \multicolumn{3}{|c|}{ Incidence (\%) } \\
\hline Type 2 diabetes complications & Total $(\mathrm{N}=134,421)$ & Male $(\mathrm{N}=72,539)$ & Female $(\mathrm{N}=61,882)$ \\
\hline Myocardial infarction & 0.40 & 0.50 & 0.29 \\
\hline Major amputations & 0.08 & 0.09 & 0.06 \\
\hline Avoidable hospitalisations & 5.50 & 5.81 & 5.14 \\
\hline Avoidable hospitalisations because of DM & 0.51 & 0.52 & 0.50 \\
\hline
\end{tabular}


Table 3 Logistic regressions of diabetes-related complications adjusted according to age and sex

\begin{tabular}{|c|c|c|c|c|c|c|c|c|c|c|c|c|c|c|c|c|c|c|c|c|}
\hline \multirow[b]{2}{*}{ Features } & \multicolumn{2}{|c|}{$\begin{array}{l}\text { Ischaemic heart } \\
\text { disease }\end{array}$} & \multicolumn{2}{|c|}{ Renal failure } & \multicolumn{2}{|c|}{ Stroke } & \multicolumn{2}{|c|}{ Heart failure } & \multicolumn{2}{|c|}{$\begin{array}{l}\text { Peripheral } \\
\text { neuropathy }\end{array}$} & \multicolumn{2}{|c|}{ Foot ulcers } & \multicolumn{2}{|c|}{ Retinopathy } & \multicolumn{2}{|c|}{$\begin{array}{c}\text { Avoidable } \\
\text { hospitalisations }\end{array}$} & \multicolumn{2}{|c|}{$\begin{array}{c}\text { Myocardial } \\
\text { infarction }\end{array}$} & \multicolumn{2}{|c|}{$\begin{array}{c}\text { Major } \\
\text { amputations }\end{array}$} \\
\hline & OR & $P$ value & OR & $P$ value & OR & $P$ value & OR & $P$ value & OR & $P$ value & OR & $P$ value & OR & $P$ value & OR & $P$ value & OR & $P$ value & OR & $P$ value \\
\hline \multicolumn{21}{|l|}{ Sex } \\
\hline Males (ref) & 1.0 & & 1.0 & & 1.0 & & 1.0 & & 1.0 & & 1.0 & & 1.0 & & 1.0 & & 1.0 & & 1.0 & \\
\hline Females & 0.4 & $<0.001$ & 0.7 & $<0.001$ & 0.7 & $<0.001$ & 0.9 & $<0.001$ & 1.1 & 0.033 & 0.9 & 0.113 & 1.0 & 0.943 & 0.7 & $<0.0001$ & 0.5 & $<0.001$ & 0.5 & 0.004 \\
\hline \multicolumn{21}{|l|}{ Age bands } \\
\hline Range 35-39 (ref) & 1.0 & & 1.0 & & 1.0 & & 1.0 & & 1.0 & & 1.0 & & 1.0 & & 1.0 (ref) & & & & & \\
\hline Range 40-44 & 2.5 & 0.013 & 1.1 & 0.779 & 2.7 & 0.111 & 4.1 & 0.181 & 1.7 & 0.317 & 1.3 & 0.572 & 1.0 & 0.854 & 1.1 & 0.681 & 1.0 (ref) & & & \\
\hline Range 45-49 & 4.5 & $<0.001$ & 1.5 & 0.181 & 5.6 & 0.004 & 7.8 & 0.043 & 2.1 & 0.115 & 1.6 & 0.348 & 1.7 & 0.003 & 0.9 & 0.73 & 0.98 & 0.976 & & \\
\hline Range 50-54 & 8.2 & $<0.001$ & 1.6 & 0.085 & 7.7 & $<0.001$ & 9.0 & 0.029 & 2.6 & 0.040 & 2.3 & 0.077 & 1.6 & 0.004 & 1 & 0.881 & 1.4 & 0.481 & 1.0 (ref) & \\
\hline Range 55-59 & 10.7 & $<0.001$ & 2.2 & 0.004 & 10.3 & $<0.001$ & 14.2 & 0.008 & 2.6 & 0.040 & 1.9 & 0.153 & 1.9 & $<0.001$ & 1.1 & 0.718 & 1.3 & 0.61 & 1.3 & 0.678 \\
\hline Range 60-64 & 11.6 & $<0.001$ & 3.0 & $<0.001$ & 14.5 & $<0.001$ & 19.5 & 0.003 & 2.8 & 0.022 & 2.5 & 0.045 & 2.1 & $<0.001$ & 1.2 & 0.353 & 1.2 & 0.705 & 0.5 & 0.365 \\
\hline Range 65-69 & 13.9 & $<0.001$ & 4.1 & $<0.001$ & 18.8 & $<0.001$ & 23.8 & 0.002 & 3.0 & 0.015 & 2.6 & 0.038 & 2.2 & $<0.001$ & 1.4 & 0.114 & 1.2 & 0.747 & 1.6 & 0.445 \\
\hline Range 70-74 & 16.8 & $<0.001$ & 6.1 & $<0.001$ & 25.5 & $<0.001$ & 35.8 & $<0.001$ & 3.0 & 0.016 & 3.5 & 0.006 & 2.2 & $<0.001$ & 1.8 & 0.006 & 1.5 & 0.349 & 3.1 & 0.069 \\
\hline Range 75-79 & 21.0 & $<0.001$ & 10.0 & $<0.001$ & 33.6 & $<0.001$ & 62.6 & $<0.001$ & 3.0 & 0.015 & 4.8 & 0.001 & 2.3 & $<0.001$ & 2.8 & $<0.001$ & 2.2 & 0.086 & 2.2 & 0.217 \\
\hline Range 80-84 & 23.7 & $<0.001$ & 14.2 & $<0.001$ & 48.1 & $<0.001$ & 94.9 & $<0.001$ & 3.0 & 0.015 & 6.9 & $<0.001$ & 2.2 & $<0.001$ & 3.8 & $<0.001$ & 2.5 & 0.044 & 3.8 & 0.03 \\
\hline Range 85 and over & 26.5 & $<0.001$ & 21.6 & $<0.001$ & 65.5 & $<0.001$ & 156.3 & $<0.001$ & 2.2 & 0.083 & 10.5 & $<0.001$ & 1.5 & 0.011 & 5.5 & $<0.001$ & 3.5 & 0.007 & 3.7 & 0.037 \\
\hline
\end{tabular}

$\mathrm{OR}=$ Odds ratio; ref $=$ reference. Statistically significant subgroups are those with $P$ value $<0.05$. 
women than in men, while the prevalence of ischaemic heart disease and stroke was higher in men than women.

When logistic regressions were applied, women with type 2 diabetes mellitus presented a lower probability than men of suffering from ischaemic heart disease, renal failure, stroke, heart failure, foot ulcers and retinopathy (approximately 58\%, 30\%, 35\%, 14\%, 6\% and 1\% less respectively), and all the analyses were statistically significant except the last two chronic diseases mentioned (Table 3). In addition, women also presented a $32 \%$ lower probability of suffering avoidable hospitalisations $(P<0.001)$, a $50 \%$ lower probability of myocardial infarction $(P<0.001)$ and a $45 \%$ lower probability for major amputations $(P=0.004)$ than men. The only condition where females presented a higher probability $(10.4 \%)$ of suffering than males was peripheral neuropathy.

Age was also an important factor in the complications (Table 3). The probability of suffering from one of these complications increased significantly with age. Since in myocardial infarction there are no people in the age group 35-39, the following group was taken as reference; the same applied to major amputations where the 50-54 age group was taken as reference. Compared to the 3539 age group, the over 85 age group was not statistically significant for peripheral neuropathy. Moreover, for myocardial infarction and major amputations only age over 79 years was statistically significant for the analysis.

\section{Unrelated chronic conditions}

The relationship with multimorbidity in year 4 of the study for this group of patients is shown in Table 4. It shows the percentage of patients in relation to the number of pathologies they suffer, where 1 represents diabetes type 2, 2 represents diabetes plus one chronic disease, and so on. For both sexes it is observed that

Table 4 Number (proportion) of people with type 2 diabetes in relation to number of chronic diseases

\begin{tabular}{lrrr}
\hline $\begin{array}{l}\text { Number of } \\
\text { pathologies }\end{array}$ & Total N (\%) & Male (N) & Female (N) \\
\hline 1 & $12,031(9.64)$ & $7,849(11.65)$ & $4,182(7.28)$ \\
2 & $26,946(21.59)$ & $15,676(23.27)$ & $11,270(19.63)$ \\
3 & $27,312(21.89)$ & $14,683(21.80)$ & $12,629(21.99)$ \\
4 & $21,230(17.01)$ & $10,795(16.03)$ & $10,435(18.17)$ \\
5 & $14,664(11.15)$ & $7,224(10.73)$ & $7,440(12.96)$ \\
6 & $9,139(7.32)$ & $4,487(6.66)$ & $4,652(8.10)$ \\
7 & $5,749(4.61)$ & $2,779(4.13)$ & $2,970(5.17)$ \\
8 & $3,446(2.76)$ & $1,690(2.51)$ & $1,756(3.06)$ \\
9 & $1,992(1.60)$ & $1,021(1.52)$ & $971(1.69)$ \\
10 or more & $2,272(1.82)$ & $1,152(1.71)$ & $1,120(1.95)$ \\
\hline
\end{tabular}

two chronic diseases plus diabetes is the most common combination. Almost 30\% suffer from five or more chronic diseases, and only $9.64 \%$ are free from other pathologies.

Table 5 shows the prevalence of patients with type 2 diabetes, in general and according to sex, who suffer from each of the 44 chronic diseases. Overall, the most common diseases were hypertension (73.71\%), dyspepsia (13.81\%), anxiety (12.75\%), and degenerative joint disease (11.72\%). Among men the study revealed hypertension (73.23\%), prostatic hypertrophy (13.48\%), atrial fibrillation (12.15\%) and COPD (12.09\%) as the most common diseases. Among women, the most prevalent conditions were hypertension $(73.54 \%)$, anxiety $(12.75 \%)$, dyspepsia (16.7\%), degenerative joint disease (15.79\%) and depression $(14.78 \%)$. In patients with type 2 diabetes, no sex differences for deafness $(P=0.07)$, immunological disease $(P=0.25)$, chronic haematological disease $(P=0.09)$, epilepsy $(P=0.46)$, chronic sinusitis $(P=0.89)$, learning disability $(P=0.12)$ and ADHD $(P=0.31)$ were found.

\section{Discussion}

Compared with other studies [26-28], we have obtained lower rates of incidence for avoidable hospitalisations, acute myocardial infarction and major amputations. Moreover, as Vamos et al. [26], we have found that sex was statistically significant for major amputation and women presented a $45 \%$ lower probability than men of being affected; the same applied to myocardial infarction (50\% lower) and for avoidable hospitalisations (32\% lower).

In this study, we could see a reduction in the rate of incidence of diabetes-related complications from 2007 to 2011. Adequate control of type 2 diabetes risk factors is high in the Basque population [29]. In addition, other studies have reported decreasing incidence of several complications such as amputations $[26,30,31]$ and preventable hospitalisations [32]. Vamos et al. [26] found that the incidence for amputations decreased by $9.1 \%$ in the four-year study period and a series of studies.

The outcomes of chronic complications, such as stroke and ischaemic heart disease are similar to those observed in other Spanish studies [33,34]. Men had a higher prevalence than women of ischaemic heart disease and stroke. Indeed, sex was statistically significant for all analyses except foot ulcers and retinopathy; women reported approximately a 58\%, 30\%, 35\% and $14 \%$ lower probability than men of developing ischaemic heart disease, renal failure, stroke and heart failure, respectively. Furthermore, the probability of suffering one of these complications increased significantly with age.

The prevalence of two or more chronic diseases in addition to type 2 diabetes mellitus was $68.8 \%$. This was 
Table 5 Prevalence of $\mathbf{4 4}$ chronic diseases in type $\mathbf{2}$ diabetes patients

\begin{tabular}{|c|c|c|c|c|}
\hline Chronic disease & Overall (\%) & Males (\%) & Females (\%) & Differences between sexes \\
\hline Hypertension & $73.71 \%$ & $73.23 \%$ & $73.54 \%$ & $<0.001$ \\
\hline Dyspepsia & $13.81 \%$ & $11.36 \%$ & $16.70 \%$ & $<0.001$ \\
\hline Prostatic hypertrophy & - & $13.48 \%$ & - & - \\
\hline Anxiety & $12.75 \%$ & $8.54 \%$ & $18.10 \%$ & $<0.001$ \\
\hline Degenerative joint disease & $11.72 \%$ & $7.79 \%$ & $15.79 \%$ & 0.002 \\
\hline Atrial Fibrillation & $10.40 \%$ & $12.15 \%$ & $8.54 \%$ & $<0.001$ \\
\hline Depression & $9.77 \%$ & $5.47 \%$ & $14.78 \%$ & $<0.001$ \\
\hline Malignant neoplasms & $8.86 \%$ & $11.17 \%$ & $6.96 \%$ & $<0.001$ \\
\hline Chronic heart disease, other & $8.57 \%$ & $10.77 \%$ & $6.09 \%$ & $<0.001$ \\
\hline Emphysema, chronic bronchitis, COPD & $8.23 \%$ & $12.09 \%$ & $4.50 \%$ & $<0.001$ \\
\hline Hypothyroidism & $6.22 \%$ & $2.31 \%$ & $11.31 \%$ & $<0.001$ \\
\hline Low back pain & $5.82 \%$ & $4.34 \%$ & $7.65 \%$ & $<0.001$ \\
\hline Dementia & $5.05 \%$ & $4.17 \%$ & $5.80 \%$ & $<0.001$ \\
\hline Osteoporosis & $4.46 \%$ & $0.83 \%$ & $8.26 \%$ & $<0.001$ \\
\hline Gout & $3.72 \%$ & $5.75 \%$ & $1.44 \%$ & $<0.001$ \\
\hline Deafness & $3.50 \%$ & $3.52 \%$ & $3.41 \%$ & 0.071 \\
\hline Asthma (currently under treatment) & $3.26 \%$ & $1.99 \%$ & $4.78 \%$ & $<0.001$ \\
\hline Chronic hepatopancreatic diseases & $3.25 \%$ & $3.91 \%$ & $2.29 \%$ & $<0.001$ \\
\hline Diverticular disease & $2.80 \%$ & $2.58 \%$ & $3.03 \%$ & $<0.001$ \\
\hline Peripheral vascular disease & $2.50 \%$ & $3.96 \%$ & $0.97 \%$ & $<0.001$ \\
\hline Rheumatoid arthritis and others & $2.40 \%$ & $2.10 \%$ & $2.78 \%$ & $<0.001$ \\
\hline Errors of metabolism and chromosomopathies & $2.15 \%$ & $2.51 \%$ & $1.69 \%$ & $<0.001$ \\
\hline Parkinson's disease & $1.88 \%$ & $1.83 \%$ & $1.99 \%$ & $<0.001$ \\
\hline Muscular dystrophy or paralysis & $1.53 \%$ & $1.73 \%$ & $1.33 \%$ & 0.005 \\
\hline Schizophrenia & $1.50 \%$ & $1.24 \%$ & $1.81 \%$ & $<0.001$ \\
\hline Chronic constipation & $1.07 \%$ & $1.04 \%$ & $1.17 \%$ & $<0.001$ \\
\hline Alcohol abuse & $1.00 \%$ & $1.46 \%$ & $0.40 \%$ & $<0.001$ \\
\hline Viral Hepatitis & $0.81 \%$ & $0.84 \%$ & $0.71 \%$ & $<0.001$ \\
\hline Psoriasis or eczema & $0.76 \%$ & $0.87 \%$ & $0.63 \%$ & $<0.001$ \\
\hline Immunological diseases & $0.63 \%$ & $0.66 \%$ & $0.63 \%$ & 0.245 \\
\hline Irritable bowel syndrome & $0.60 \%$ & $0.38 \%$ & $0.87 \%$ & $<0.001$ \\
\hline Bronchiectasis & $0.59 \%$ & $0.75 \%$ & $0.47 \%$ & 0.003 \\
\hline Chronic Haematological Diseases & $0.58 \%$ & $0.60 \%$ & $0.59 \%$ & 0.085 \\
\hline Epilepsy (currently under treatment) & $0.55 \%$ & $0.58 \%$ & $0.53 \%$ & 0.457 \\
\hline Inflammatory bowel disease & $0.50 \%$ & $0.52 \%$ & $0.47 \%$ & 0.040 \\
\hline Post-transplant state & $0.37 \%$ & $0.44 \%$ & $0.26 \%$ & $<0.001$ \\
\hline Chronic Sinusitis & $0.26 \%$ & $0.25 \%$ & $0.28 \%$ & 0.891 \\
\hline Learning Disabilities & $0.13 \%$ & $0.11 \%$ & $0.17 \%$ & 0.115 \\
\hline HIV & $0.12 \%$ & $0.15 \%$ & $0.06 \%$ & $<0.001$ \\
\hline Migraine & $0.11 \%$ & $0.04 \%$ & $0.23 \%$ & $<0.001$ \\
\hline Substance Abuse & $0.11 \%$ & $0.14 \%$ & $0.05 \%$ & $<0.001$ \\
\hline
\end{tabular}


Table 5 Prevalence of $\mathbf{4 4}$ chronic diseases in type 2 diabetes patients (Continued)

\begin{tabular}{lcccc}
\hline Multiple sclerosis & $0.07 \%$ & $0.05 \%$ & $0.10 \%$ & 0.033 \\
Anorexia, bulimia & $0.03 \%$ & $0.01 \%$ & $0.06 \%$ & $<0.001$ \\
ADHD & $0.005 \%$ & $0.002 \%$ & $0.01 \%$ & 0.311 \\
\hline
\end{tabular}

Stratified by sex and all prevalence is adjusted by age and sex (in overall case). Statistically significant differences are those with $P$ value $<0.05$. ADHD: Attention Deficit Hyperactivity Disorder; COPD: Chronic Obstructive Pulmonary Disease; HIV: Human Immunodeficiency Virus.

equivalent to that recorded in a cohort of Irish primary care patients (68.4\%) [17]. In our analysis of sex-related differences for multimorbidity, men presented a greater prevalence of hypertension, prostatic hypertrophy, atrial fibrillation and COPD; women presented greater prevalence of hypertension, anxiety, dyspepsia, degenerative joint disease and depression.

Our study has several strengths. First, Osakidetza is a healthcare system with universal coverage. This makes it possible for our study to include almost all the population with type 2 diabetes in the geographical area under study; selection bias is thus avoided. Second, it makes use of a database which contains information from primary care, specialty care, hospital care, and prescriptions. This is relevant, as other authors have established that the use of just one source can produce inaccurate calculations [35,36], while the complementary use of various sources contributes to a better description of the persons' health problems [37].

The study limitations correspond to the use of administrative databases, which only contain information about patients who seek healthcare. Therefore, the prevalence of complications can only reflect known cases and exclude cases not known by the patient or healthcare personnel.

Type 2 Diabetes Mellitus is a disease associated with reduced quality of life due to associated chronic complications that develop throughout the natural development of the disease. Adequate metabolic control may help reduce the risks of complications over the longterm. The epidemiological information available in the BAC gives an idea of its importance and the growing impact on the population and health services.

This study provides relevant epidemiological information about the prevalence and incidence of diabetesrelated complications, in addition to, multimorbidity in this patient group. Moreover, it has been utilised to confirm differences between sex and age that could be employed to define interventions focused on certain patient profiles. Moreover, it could even be used as a support for a future diabetes registry to improve the disease monitoring and research in our community.

\section{Conclusions}

The high prevalence of multimorbidity and the diversity of chronic conditions complicate disease management in this group and show the need for a holistic approach in its clinical care and education. Furthermore, the need to educate patients regarding self-care and to pay special attention to the implications of polypharmacy must be emphasised [38]. In the same way, there is a need to perform further research to reach a consensus on developing Clinical Practice Guidelines focused on patients with multiple pathologies, thereby reducing the risk of inappropriate clinical management and patient safety issues such as drug interactions.

Chronic complications of diabetes have a relevant impact on the population with type 2 diabetes. Therefore, an expansion of epidemiological knowledge and improved disease monitoring should be a public health priority, to address the social and health implications and to develop interventions that enable better management of these patients.

\section{Abbreviations}

ACSC: Ambulatory Care Sensitive Condition; ATC: Anatomical, Therapeutic, Chemical classification system; BAC: Basque Autonomous Community; CVRF: Cardiovascular Risk Factor; ICD: International Classification of Disease; MBDS: Minimum Basic Data Set; PREST: Basque Country population stratification programme; SNS: Spanish National Health System.

\section{Competing interests}

The authors have no conflict of interest associated with this manuscript to declare. The funding organisation, Sanofi-Aventis, had no role in the design and conduct of the study, the collection, management, analysis and interpretation of data, or the preparation, review and approval of the manuscript.

\section{Authors' contributions}

EAM, JFO, NTP and RNS designed the study. EAM and JFO took part in data collection. EAM analysed the data. JIFE, JMAA, MLMG, PEL and SG provided clinical support. All authors contributed to data interpretation, and preparation and revision of the manuscript. All authors read and approved the final manuscript.

\section{Acknowledgements}

The authors wish to acknowledge the support received from Ricardo Samper Ochotorena, in addition to the funding collaboration and support received by the Sanofi-Aventis pharmaceutical company, in connection with increasing diabetes awareness.

Edurne Alonso-Morán is the guarantor of this work and, as such, had full access to all data in the study and takes responsibility for integrity of the data and accuracy of the data analysis.

\section{Author details}

${ }^{1} \mathrm{O}+$ berri, Basque Institute for Healthcare Innovation, Torre del BEC (Bilbao Exhibition Centre), Ronda de Azkue 1, 48902 Barakaldo, Spain. ${ }^{2}$ Osakidetza, Basque Health Service, Astrabudua Health Centre, Mezo 35, 48950 Erandio, Spain. ${ }^{3}$ Osakidetza, Basque Health Service, San Miguel Health Centre, Garbileku s/n, 48970 Basauri, Spain. ${ }^{4}$ Department of Health, Donostia-San 
Sebastián 1, 01010 Vitoria-Gasteiz, Spain. ${ }^{5}$ Osakidetza, Basque Health Service, Uribe Country Manager, Alango 30, 48992 Getxo, Spain. ${ }^{6}$ Osakidetza, Basque Health Service, Zumaia Health Centre, Basadi 15, 20750 Zumaia, Spain. ${ }^{7}$ Endocrinology and Nutrition Department, Osakidetza, Basque Health Service, Cruces University Hospital, Plaza de Cruces s/n, 48903 Barakaldo, Spain. ${ }^{8}$ The University of the Basque Country, Leioa, Biscay, Spain. ${ }^{9}$ Spanish Biomedical Research Centre in Diabetes and Associated Metabolic Disorders, CIBERDEM, Madrid, Spain.

Received: 15 July 2014 Accepted: 3 October 2014

Published: 10 October 2014

\section{References}

1. International Diabetes Federation: IDF Diabetes Atlas. 6th edition. Brussels, Belgium: International Diabetes Federation; 2013. Available from: http:// www.idf.org/diabetesatlas. [Accessed 27 January 2014]

2. Soriguer F, Goday A, Bosch-Comas A, Bordiu E, Calle-Pascual A, Carmena R, Casamitjana R, Castano L, Castell C, Catala M, Delgado E, Franch J, Gaztambide S, Girbes J, Gomis R, Gutierrez G, Lopez-Alba A, MartinezLarrad MT, Menendez E, Mora-Peces I, Ortega E, Pascual-Manich G, RojoMartinez G, Serrano-Rios M, Valdes S, Vazquez JA, Vendrell J: Prevalence of diabetes mellitus and impaired glucose regulation in Spain: the Di@bet.es Study. Diabetologia 2012, 55:88-93.

3. Emerging Risk Factors Collaboration, Seshasai SRK, Kaptoge S, Thompson A, Di Angelantonio E, Gao P, Sarwar N, Whincup PH, Mukamal KJ, Gillum RF, Holme I, Niølstad I, Fletcher A, Nilsson P, Lewington S, Collins R, Gudnason V, Thompson SG, Sattar N, Selvin E, Hu FB, Danesh J: Diabetes mellitus, fasting glucose, and risk of cause-specific death. N Engl J Med 2011, 364:829-841.

4. Gu K, Cowie CC, Harris MI: Diabetes and decline in heart disease mortality in US adults. JAMA J Am Med Assoc 1999, 281:1291-1297.

5. Nwaneri C, Cooper H, Bowen-Jones D: Mortality in type 2 diabetes mellitus: magnitude of the evidence from a systematic review and meta-analysis. Br J Diabetes Vasc Dis 2013, 13:192-207.

6. Regidor E, Franch J, Seguí M, Serrano R, Rodríguez-Artalejo F, Artola S: Traditional risk factors alone could not explain the excess mortality in patients with diabetes: a national cohort study of older Spanish adults. Diabetes Care 2012, 35:2503-2509.

7. Skyler JS: Diabetic complications. The importance of glucose control. Endocrinol Metab Clin North Am 1996, 25:243-254.

8. American Diabetes Association: Standards of medical care in diabetes-2010. Diabetes Care 2010, 33(Suppl 1):S11-S61.

9. Holman RR, Paul SK, Bethel MA, Matthews DR, Neil HAW: 10-year follow-up of intensive glucose control in type 2 diabetes. N Engl J Med 2008, 359:1577-1589.

10. Gaede P, Lund-Andersen H, Parving H-H, Pedersen O: Effect of a multifactorial intervention on mortality in type 2 diabetes. N Engl J Med 2008, 358:580-591.

11. Corbatón Anchuelo A, Cuervo Pinto R, Serrano Ríos M: La diabetes mellitus tipo 2 como enfermedad cardiovascular. Rev Esp Cardiol 2007, 7(Supl A):9-22.

12. Estrategia en Diabetes del Sistema Nacional de Salud 2012. Actualización: Sanidad 2012. Ministerio de Sanidad, Servicios sociales e Igualdad. NIPO: 680-12-047-5. http://www.observatorio.naos.aesan.msssi.gob.es/docs/docs/ documentos/estrategia_en_diabetes_del_sistema_nacional_de_salud_2012. pdf. [Accessed 13 October 2014]

13. Rijken M, van Kerkhof M, Dekker J, Schellevis FG: Comorbidity of chronic diseases: effects of disease pairs on physical and mental functioning. Qual Life Res Int J Qual Life Asp Treat Care Rehabil 2005, 14:45-55.

14. Schellevis FG, van der Velden J, van de Lisdonk E, van Eijk JT, van Weel C: Comorbidity of chronic diseases in general practice. J Clin Epidemiol 1993, 46:469-473.

15. Struijs JN, Baan CA, Schellevis FG, Westert GP, van den Bos GAM: Comorbidity in patients with diabetes mellitus: impact on medical health care utilization. BMC Health Serv Res 2006, 6:84.

16. Luijks $H$, Schermer $T$, Bor $H$, van Weel C, Lagro-Janssen T, Biermans M, de Grauw W: Prevalence and incidence density rates of chronic comorbidity in type 2 diabetes patients: an exploratory cohort study. BMC Med 2012, 10:128.

17. Teljeur C, Smith SM, Paul G, Kelly A, O'Dowd T: Multimorbidity in a cohort of patients with type 2 diabetes. Eur J Gen Pract 2013, 19:17-22.

18. Spanish Institute of Health Information: Spanish version (eCIE9MC) of the Electronic International Classification of Diseases, Ninth Revision, Clinical
Modification (ICD-9CM) (8th Ed., Version 1.1.0). 2012, https://eciemaps. mspsi.es/ecieMaps/browser/index_9_mc.html.

19. The WHO Collaborating Centre for Drug Statistics Methodology: International language for drug utilization research ATC/DDD. 2012, http://www.whocc. no/atc_ddd_index/.

20. Orueta JF, Mateos Del Pino M, Barrio Beraza I, Nuño Solinis R, Cuadrado Zubizarreta M, Sola Sarabia C: Stratification of the population in the Basque Country: results in the first year of implementation. Atencion Primaria Soc Esp Med Fam Comunitaria 2013, 45:54-60.

21. Arteagoitia-Axpe JM, González-Carril F, Rodríguez-Murua JL, Piniés-Raposo JA: Diabetes mellitus, clasificación y epidemiología. In Diabetes mellitus 2: Impacto en la salud pública y estrategias de prevención. Madrid: EMISA: 8a Monografía de la Sociedad Española de Epidemiología (SEE); 2008:11-38.

22. Registro de Altas de los Hospitales Generales del Sistema Nacional de Salud. CMBD: Norma Estatal. Ministerio de Sanidad, Servicios Sociales e Igualdad. http://www.msc.es/estadEstudios/estadisticas/cmbd.htm. [Accessed 27 January 2014]

23. Caminal J, Mundet X, Ponsà J, Sánchez E, Casanova C: Hospitalizations due to ambulatory care sensitive conditions: selection of diagnostic codes for Spain. Gac Sanit SESPAS 2001, 15:128-141.

24. Barnett K, Mercer SW, Norbury M, Watt G, Wyke S, Guthrie B: Epidemiology of multimorbidity and implications for health care, research, and medical education: a cross-sectional study. Lancet 2012, 380:37-43.

25. Orueta JF, García-Álvarez A, Alonso-Morán E, Vallejo-Torres L, Nuño-Solinis R: Socioeconomic variation in the burden of chronic conditions and health care provision-analyzing administrative individual level data from the Basque Country, Spain. BMC Public Health 2013, 13:870.

26. Vamos EP, Bottle A, Edmonds ME, Valabhji J, Majeed A, Millett C: Changes in the incidence of lower extremity amputations in individuals with and without diabetes in England between 2004 and 2008. Diabetes Care 2010, 33:2592-2597

27. Mata-Cases M, Roura-Olmeda P, Berengué-Iglesias M, Birulés-Pons M, Mundet-Tuduri X, Franch-Nadal J, Benito-Badorrey B, Cano-Pérez JF, Diabetes Study Group in Primary Health Care (GEDAPS: Grup d'Estudi de la Diabetis a I'Atenció Primària de Salut, Catalonian Society of Family and Community Medicine): Fifteen years of continuous improvement of quality care of type 2 diabetes mellitus in primary care in Catalonia, Spain. Int J Clin Pract 2012, 66:289-298.

28. Lindhardsen J, Ahlehoff O, Gislason GH, Madsen OR, Olesen JB, Torp-Pedersen C, Hansen PR: The risk of myocardial infarction in rheumatoid arthritis and diabetes mellitus: a Danish nationwide cohort study. Ann Rheum Dis 2011, 70:929-934.

29. Alonso-Morán E, Satylganova A, Orueta JF, Nuño-Solinis R: Prevalence of depression in adults with type 2 diabetes in the Basque Country: relationship with glycaemic control and health care costs. BMC Public Health 2014, 14:769.

30. Schofield CJ, Yu N, Jain AS, Leese GP: Decreasing amputation rates in patients with diabetes-a population-based study. Diabet Med I Br Diabet Assoc 2009, 26:773-777.

31. Van Houtum WH, Rauwerda JA, Ruwaard D, Schaper NC, Bakker K: Reduction in diabetes-related lower-extremity amputations in The Netherlands: 1991-2000. Diabetes Care 2004, 27:1042-1046.

32. Wang J, Imai K, Engelgau MM, Geiss LS, Wen C, Zhang P: Secular trends in diabetes-related preventable hospitalizations in the United States, 1998-2006. Diabetes Care 2009, 32:1213-1217.

33. Vinagre I, Mata-Cases M, Hermosilla E, Morros R, Fina F, Rosell M, Castell C, Franch-Nadal J, Bolíbar B, Mauricio D: Control of glycemia and cardiovascular risk factors in patients with type 2 diabetes in primary care in Catalonia (Spain). Diabetes Care 2012, 35:774-779.

34. Franch Nadal J, Artola Menéndez S, Diez Espino J, Mata Cases M, en representación de la Red de Grupos de Estudio de la Diabetes en Atención Primaria de la Salud: The evolution of quality care indicators of patients with type 2 diabetes in the Spanish primary care (1996-2007). The RedGEDAPS quality of care program. Med Clínica 2010, 135:600-607.

35. Aubé-Maurice J, Rochette L, Blais C: Divergent associations between incident hypertension and deprivation based on different sources of case identification. Chronic Dis Inj Can 2012, 32:121-130.

36. Van den Bussche H, Schäfer I, Wiese B, Dahlhaus A, Fuchs A, Gensichen J, Höfels S, Hansen H, Leicht H, Koller D, Luppa M, Nützel A, Werle J, Scherer M, Wegscheider K, Glaeske G, Schön G: A comparative study demonstrated that 
prevalence figures on multimorbidity require cautious interpretation when drawn from a single database. J Clin Epidemiol 2013, 66:209-217.

37. Orueta JF, Nuño-Solinis R, Mateos M, Vergara I, Grandes G, Esnaola S:

Monitoring the prevalence of chronic conditions: which data should we use? BMC Health Serv Res 2012, 12:365.

38. Smith SM, O'Kelly S, O'Dowd T: GPs' and pharmacists' experiences of managing multimorbidity: a "Pandora"s box'. Br J Gen Pract J R Coll Gen Pract 2010, 60:285-294.

doi:10.1186/1471-2458-14-1059

Cite this article as: Alonso-Morán et al:: The prevalence of diabetes-

related complications and multimorbidity in the population with type 2 diabetes mellitus in the Basque Country. BMC Public Health 2014 14:1059.

\section{Submit your next manuscript to BioMed Central and take full advantage of:}

- Convenient online submission

- Thorough peer review

- No space constraints or color figure charges

- Immediate publication on acceptance

- Inclusion in PubMed, CAS, Scopus and Google Scholar

- Research which is freely available for redistribution 